\title{
Research of the influence of power engineering equipment accident rate on the indicators of adequacy and the value of operating reserve of electrical power system
}

\author{
Dmitry Krupenev ${ }^{1,2, *}$, Denis Boyarkin ${ }^{2}$, Dmitrii Yakubovskii ${ }^{2}$, and Yana Severina ${ }^{1,2}$ \\ ${ }^{1}$ Melentiev Energy Systems Institute of Siberian Branch of the Russian Academy of Sciences (ESI SB RAS), 130 Lermontov Street, \\ Irkutsk, 664033, Russia \\ ${ }^{2}$ Irkutsk National Research Technical University (INRTU), 83 Lermontov Street, Irkutsk, 664074, Russia
}

\begin{abstract}
Reliable source information is necessary for a correct adequacy assessment of electric power systems. Among a wide set of initial information, coefficients of accident rates of power engineering equipment are important. The analysis of methods for determining the coefficients of accident rates of power engineering equipment, which are used in the assessment of the adequacy of electric power systems, is presented in the article, also the features of accounting for coefficients of accident rates are elicited. The experimental part of the article is showed the influence of generating aggregates accident rate on the level of operating reserve on the example of the Unified Energy System of Russia.
\end{abstract}

\section{Introduction}

The accident rate of the power engineering equipment influences in the most direct way both the indicators of adequacy of electric power systems (EPS) and the level of operating reserve. The accident rate of the power engineering equipment depends on many factors. Factors or causes of failures for each type of power engineering equipment can be booth characteristic, for example, for overhead transmission line it can be weather conditions, the level of icing on the wires, and general for the whole complex of power engineering equipment, such as the culture of operational, the level of wear (ageing), etc. [1].

The notion of failure is fundamental in reliability theory. This notion is interpreted as an event that consists in the transition of an object from one functional ability level to another lower one. The analysis of equipment failures is carried out as part of the research of a single property of reliability - failure-free operation. There are existed a row of failure-free operation indicators that characterize the object of consideration from position of how often it fails, for what time, with what speed and probability.

The influence of failures of generating aggregates and power transmission lines that included in the connections between zones or controlled sections on the reliability of electrical and capacity supply to consumer is analyzed in the study of the adequacy of electric power systems (EPS). The criterion for system failure is the occurrence of capacity deficiency among consumers. The main reason for the appearance of capacity deficiency is the power engineering equipment failures. The values of the main reliability indicators, such as the probability of a fail-free operation and the mathematical expectation of electricity sacrifice, on the basis of which the need for generating capacity reserves is assessed in further, depend on how often a capacity deficiency occurs and what is its magnitude.

Thus, the purpose of the article is to analyze the methods for determining the coefficients of accident rates of power engineering equipment and impact assessment of the values of the accident rates coefficients on the indicators of adequacy and on the level of generating capacity reservation using the example of the Unified Energy System (UES) of Russia.

\section{Determination of the power engineering equipment coefficients accident rate}

The most used method for assessment adequacy is based on the Monte-Carlo method [2,3]. One of the main steps of the methodology is the step of forming the calculated states of EPS. The calculated states is formed on the basis of simulation power engineering equipment failures that bases on coefficients of accident rate, also random deviations of capacity consumption are simulated during the assessment. Simulation of one accident event $K_{i}, i=$ $1, \ldots, I$, the probability of which is $p_{i}, i=1, \ldots, I$, occurs when playing one random number $r_{i}, i=1, \ldots, I$ from evenly distributed set $R$ on the interval [0,1]. If at the same time $r_{i}$ is in the interval $\left[0, k_{i}^{a b}\right]$, it is considered that the event has come if not, then it didn't come [4]:

$$
K_{i}=\left\{\begin{array}{l}
1, \text { if } r_{i} \in\left[0, k_{i}^{a b}\right] \\
0, \text { if } r_{i} \in\left(k_{i}^{a b}, 1\right]
\end{array}, i=1, \ldots, I .\right.
$$

In this case, it is of interest to determine the adequacy of the coefficient of accident rate $k_{i}^{a b}$ for the periods of the

\footnotetext{
Corresponding author: krupenev@isem.irk.ru
} 
calculated interval, since it directly affects the indicators of adequacy.

The coefficient of accident rate of power grid or generating equipment $k_{i}^{a b}$ characterizes the emergency repairs relative time of power equipment for a year or another period and can be determined by the following formula:

$$
k_{i}^{a \beta}=\frac{t_{i}^{a b}}{t_{\text {pacu }}}, i=1, \ldots, I,
$$

where: $t_{i}^{a b}$ down-time of power equipment in emergency repairs (issued by urgent and emergency dispatcher's request) during the retrospective period (h); $t_{\text {pacu }}$-the duration of the retrospective period (h); I- the amount of power equipment.

The retrospective period, of course, depends on the conditions of the assigned task and the available statistics on emergency downtime of power equipment. For example, if it is known, that power equipment failures have highly correlation with any climate that are characteristic of one or on other months of the year, then it is necessary to calculate the coefficient of accident rate with differentiation by months. An important condition for calculating the coefficient of accident rate is taking into account the dynamics of power equipment aging when pre-planning of the IPS development, what will influence the most directly the coefficient of accident rate. By default, the retrospective period in the formula, for example, for a year it will be equal to 8760 hours. According to [5], the coefficient of accident rate of a generating aggregate (electrical power unit) is determined by the following formula:

$$
k_{i}^{a b}=\frac{t_{i}^{a \beta}}{t_{I}^{p a \sigma}+t_{i}^{p e 3}}, i=1, \ldots, I,
$$

where: $t_{I}^{\text {pa }}$ - the duration of the generating aggregate operating time $(\mathrm{h}) ; t_{i}^{p e s}$ - the duration of the of generating aggregate in reserve $(h)$.

Expression (3) can be generalized to the whole set of analyzed power equipment. If we analyze expression (3), that the denominator arises a question, namely $t_{i}^{\text {pes }}$. Pertinently, during the period when the power facilities is in a state of cold reserve, it can't fail, therefore, at least it is necessary to exclude from the denominatort $t_{i}^{\text {pez }}$.

In fact, the power facility can be in the following states: in-service, emergency, scheduled repair, reserve. Two states have to consider when determining the coefficient of accident rate: in-service and emergency, therefore the most accurate assessment of the coefficient of accident rate can be obtained using the following expression:

$$
k_{i}^{a \beta}=\frac{t_{i}^{a \beta}}{t_{i}^{p a \sigma}+t_{i}^{a b}}, i=1, \ldots, I,
$$

For example, in in modern conditions operation of generating aggregate the operating time can be only half the calculation period, i.e. 4380 hours, while the aggregate can be in emergency repair for 10 days or 240 hours and in scheduled repair for 8 days or 192 hours, the rest 3948 hours be in reserve. Let's calculate the coefficient of accident rate by (2), (3) and (4): $0.0274 ; 0.0288 ; 0.0519$ respectively. Thus, as can be seen from the presented example, which is very indicative, the coefficient of accident rate for different approaches to its definition can differ by 2 times.

\section{Accident rate indicators of power equipment operated in the UPS of Russia}

As already noted, obtaining actual coefficient of accident rate that reflect the modern state of power equipment [6,7] is important in assessing adequacy, but for some equipment, the differentiation of the coefficient of accident rate by the characteristic intervals of the calculation period is important. So, for overhead power transmission line the coefficient of accident rate depend on weather conditions in different periods of the year. Statistical processing of emergency downtime of power transmission lines for lines included in the controlled sections of the UPS of Russia was carried out. In fig. 1 shows the results of there native values of the accident rate of power transmission lines for the IPS included in the UPS of Russia (the values are determined relative to the maximum).

Data on the accident rate of power transmission lines, presented in Fig. 1 were obtained after processing of retrospective data over a 10 -year period. As can be seen from the presented dependences in fig. 1 , the relative accident rates of power transmission lines changes significantly depending on the months of the year and has different peaks and dips in different IPS. So the peak is in the spring months, and the dip is observed in the summer months in the IPS of the East. Peaks are observed in the summer months in the IPS of Siberia, which may be connected with forest fires, as well as the loading of many power transmission lines during the flood periods. Summer and autumn peaks are attended in the IPS of the Urals, spring and autumn peaks are in the IPS of the Middle Volga. Spring and summer peaks are observed in the IPS of the South, spring and autumn peaks are in IPS of the Center. Peaks are occurred at the end of summer and beginning of autumn in the IPS of the North-West.

The coefficients of accident rate for generating aggregates that exploited in the UPS of Russia were determined by dependencies (2), (3) and (4). Data of part on the IPS included in the UES of Russia is presented in table 1 .The actual time during which the generating aggregates were in reserve was not known when calculating the coefficients of accident rate. We are talking about aggregates that exploited, first, at TPP, at NPP, as a rule, the operation of such aggregates is strictly regulated, but the loading of aggregates of HPP depends on the flood period. In modern operating conditions, the time of downtimes in the reserve for generating aggregates of TPP is significant and can be up to $50 \%$ of the estimated time, it was accepted, that the generating aggregates at TPP are in reserve from 30 to $50 \%$ from the estimated time during calculating the coefficient of accident rate. Also, the values of the coefficients of accident rate from [8] are presented in table 1. 

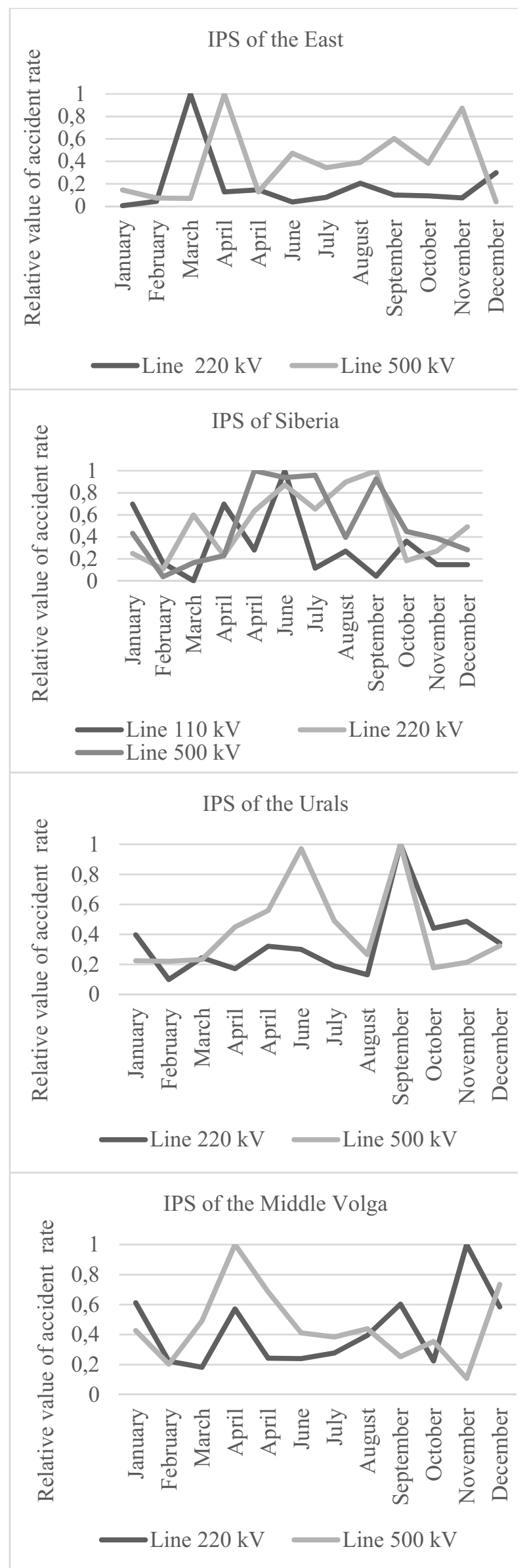
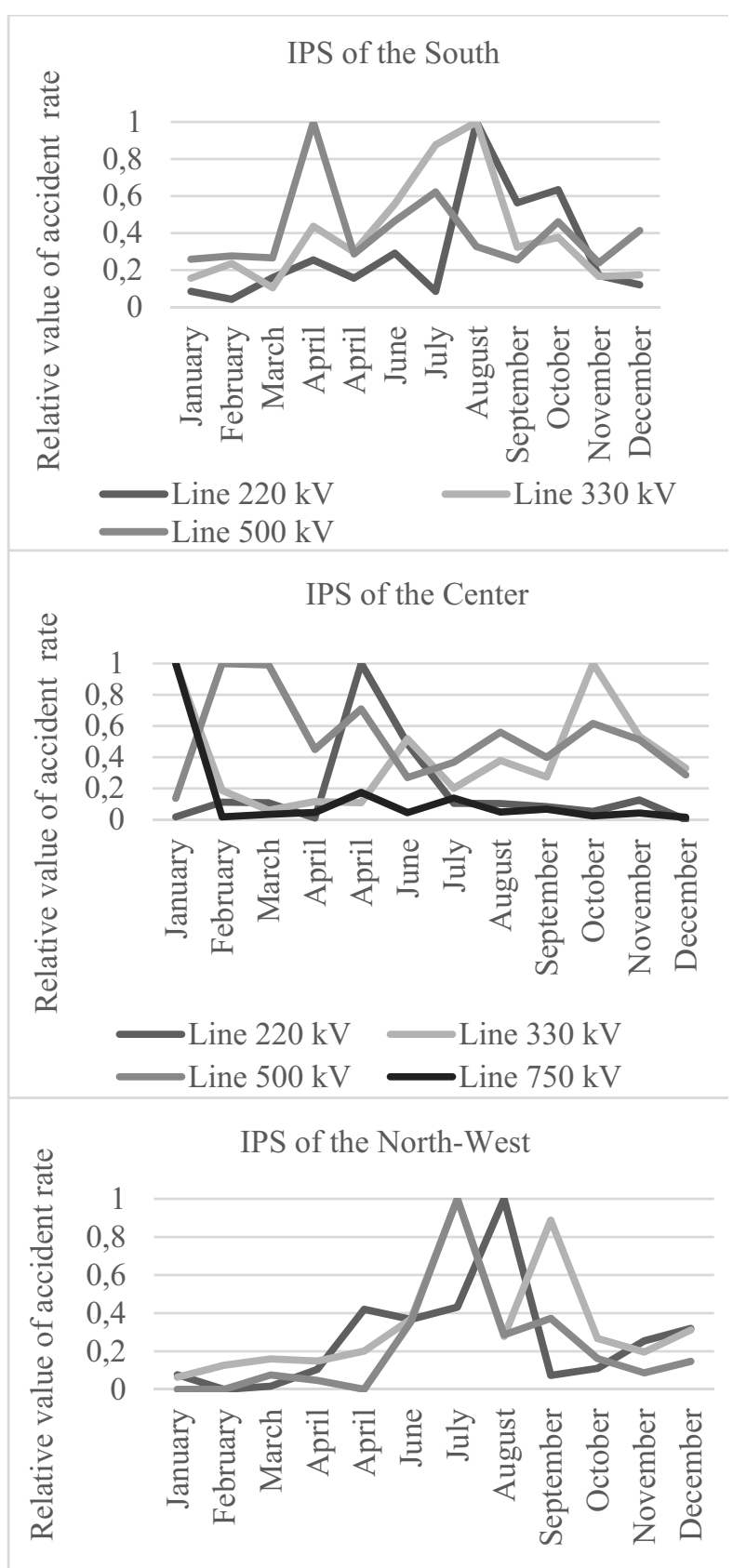

Line $220 \mathrm{kV} \longrightarrow$ Line $330 \mathrm{kV}$

Line $750 \mathrm{kV}$

Fig. 1. Relative accident rates of power transmission lines in various IPS

As you can see, the values of the coefficients of accident rate, determined by different methods, are different. Also, if the calculated values are compared with the values of the coefficients of accident rate presented in [8], then we can conclude that the accident rate of the generating equipment under modern operating conditions is usually lower than in [8]. There are groups of equipment where the coefficients of accident rate determined by (4), took values higher than in [8]. 
Table 1. The coefficients of accident rate of generating aggregates of part in the UES of Russia, calculated using on different

\begin{tabular}{|c|c|c|c|c|c|c|c|}
\hline \multirow{2}{*}{$\begin{array}{c}\text { Type of } \\
\text { power } \\
\text { plant }\end{array}$} & \multirow{2}{*}{$\begin{array}{l}\text { Amount of } \\
\text { aggregates } \\
\text { (pcs.) }\end{array}$} & \multirow{2}{*}{$\begin{array}{c}\text { Diapason of } \\
\text { years of input }\end{array}$} & \multirow{2}{*}{$\begin{array}{c}\text { Diapason of } \\
\text { installed capacity } \\
\text { of } \\
\text { aggregates, MW }\end{array}$} & \multicolumn{4}{|c|}{ Accident rates } \\
\hline & & & & (2) & (3) & (4) & {$[8$} \\
\hline \multicolumn{8}{|c|}{ IPS of the North-West } \\
\hline NPP & 16 & $2010-2010$ & $151-451$ & 0,0031 & 0,0036 & 0,0036 & 0,0650 \\
\hline \multirow[t]{3}{*}{ HPP } & 62 & $1926-2016$ & $0-150$ & 0,0106 & 0,0111 & 0,0110 & 0,0050 \\
\hline & 49 & $1952-2014$ & $26-70$ & 0,0073 & 0,0077 & 0,0076 & 0,0050 \\
\hline & 1 & $1984-1984$ & $71-150$ & 0,0127 & 0,0133 & 0,0131 & 0,0050 \\
\hline \multirow[t]{6}{*}{ TPP } & 66 & $1945-2014$ & $0-25$ & 0,0254 & 0,0277 & 0,0526 & 0,0200 \\
\hline & 67 & $1951-2016$ & $26-70$ & 0,0137 & 0,0145 & 0,0254 & 0,0200 \\
\hline & 35 & $1976-2013$ & $71-150$ & 0,0138 & 0,0148 & 0,0266 & 0,0200 \\
\hline & 20 & $2010-2012$ & $151-250$ & 0,0154 & 0,0174 & 0,0334 & 0,0450 \\
\hline & 7 & $2010-2012$ & $251-450$ & 0,0029 & 0,0033 & 0,0050 & 0,0550 \\
\hline & 5 & $2010-2010$ & 451 and higher & 0,0053 & 0,0053 & 0,0098 & 0,0550 \\
\hline \multicolumn{8}{|c|}{ IPS of the Center } \\
\hline \multirow[t]{2}{*}{ NPP } & 2 & $2010-2010$ & $151-250$ & 0,0016 & 0,0018 & 0,0018 & 0,0550 \\
\hline & 22 & $2010-2016$ & 451 and higher & 0,0053 & 0,0071 & 0,0071 & 0,0750 \\
\hline HPP & 8 & $2010-2010$ & $26-70$ & 0,0057 & 0,0061 & 0,0060 & 0,0050 \\
\hline \multirow[t]{6}{*}{ TPP } & 86 & $1953-2011$ & $0-25$ & 0,0117 & 0,0124 & 0,0228 & 0,0200 \\
\hline & 85 & $1953-2012$ & $26-70$ & 0,0113 & 0,0121 & 0,0187 & 0,0200 \\
\hline & 84 & $1977-2014$ & $71-150$ & 0,0056 & 0,0060 & 0,0105 & 0,0200 \\
\hline & 32 & $2010-2010$ & $151-250$ & 0,0152 & 0,0171 & 0,0316 & 0,0450 \\
\hline & 30 & $2010-2010$ & $251-450$ & 0,0105 & 0,0118 & 0,0244 & 0,0550 \\
\hline & 3 & $2010-2010$ & 451 and higher & 0,0138 & 0,0179 & 0,0423 & 0,0550 \\
\hline \multicolumn{8}{|c|}{ IPS of the South } \\
\hline NPP & 4 & $1986-2018$ & 451 and higher & 0,0098 & 0,0113 & 0,0112 & 0,0750 \\
\hline \multirow[t]{4}{*}{ HPP } & 57 & $1934-2016$ & $0-25$ & 0,0165 & 0,0173 & 0,0170 & 0,0050 \\
\hline & 18 & $1952-2015$ & $26-70$ & 0,0046 & 0,0047 & 0,0047 & 0,0050 \\
\hline & 24 & $1985-2010$ & $71-150$ & 0,0092 & 0,0097 & 0,0096 & 0,0050 \\
\hline & 8 & $1974-2010$ & $151-250$ & 0,0281 & 0,0300 & 0,0291 & 0,0050 \\
\hline \multirow[t]{5}{*}{ TPP } & 49 & $1950-2015$ & $0-25$ & 0,0118 & 0,0123 & 0,0219 & 0,0200 \\
\hline & 34 & $1958-2015$ & $26-70$ & 0,0195 & 0,0211 & 0,0394 & 0,0200 \\
\hline & 27 & $1966-2013$ & $71-150$ & 0,0238 & 0,0260 & 0,0391 & 0,0200 \\
\hline & 12 & $1970-2010$ & $151-250$ & 0,0146 & 0,0156 & 0,0253 & 0,0450 \\
\hline & 18 & $1975-2016$ & $251-450$ & 0,0191 & 0,0218 & 0,0427 & 0,0550 \\
\hline \multicolumn{8}{|c|}{ IPS of the MiddleVolga } \\
\hline NPP & 4 & $1985-1993$ & 451 and higher & 0,0065 & 0,0074 & 0,0073 & 0,0750 \\
\hline \multirow[t]{3}{*}{ HPP } & 1 & $2015-2015$ & $0-25$ & 0,0027 & 0,0028 & 0,0028 & 0,0050 \\
\hline & 32 & $1967-2016$ & $26-70$ & 0,0018 & 0,0019 & 0,0019 & 0,0050 \\
\hline & 52 & $1979-2010$ & $71-150$ & 0,0044 & 0,0046 & 0,0046 & 0,0050 \\
\hline \multirow[t]{4}{*}{ TPP } & 35 & $1942-2010$ & $0-25$ & 0,0139 & 0,0149 & 0,0241 & 0,0200 \\
\hline & 62 & $1952-2014$ & $26-70$ & 0,0098 & 0,0102 & 0,0170 & 0,0200 \\
\hline & 83 & $1965-2015$ & $71-150$ & 0,0095 & 0,0101 & 0,0208 & 0,0200 \\
\hline & 16 & $1963-2014$ & $151-250$ & 0,0049 & 0,0053 & 0,0079 & 0,0450 \\
\hline
\end{tabular}




\section{Experimental research}

As a part of the experimental studies, the task was set to determine the difference in the value of the operating reserve for different standard values of the probability of fail-free operation taking into account the different coefficients of accident rate of generating equipment. The values obtained on (2) and from [8] were taken as the compared coefficients of accident rate. The researches were carried out on the scheme of the UPS of Russia (excluding the IPS of the East). The main characteristics (consumption, generation) were obtained on the basis of [9] for 2022. Fig.2 shows the separation of the UES of Russia scheme on reliability zones.

Table 2 provides information of the capacity balance of the UES of Russia (without IPS of the East) per hour of the coincident demand.
Table 2. Capacity balance in the UPS of Russia (without IPS of the East), original variant on level at 2022

\begin{tabular}{|l|c|}
\hline Available capacity, MW & 206259 \\
\hline Coincident demand, MW & 158686 \\
\hline Generating reserve, MW & 47573 \\
\hline Redundancy factor, $\%$ & 30 \\
\hline
\end{tabular}

Table 3 provides information on calculations to determine the generating capacity reserve corresponding to the standard values of the probability of fail-free operation at the level of $0.999 ; 0.996 ; 0.987$. Fig.3 shows the dependence of the generating capacity reserve on the probability of fail-free operation in the reliability zones of the UPS of Russia.

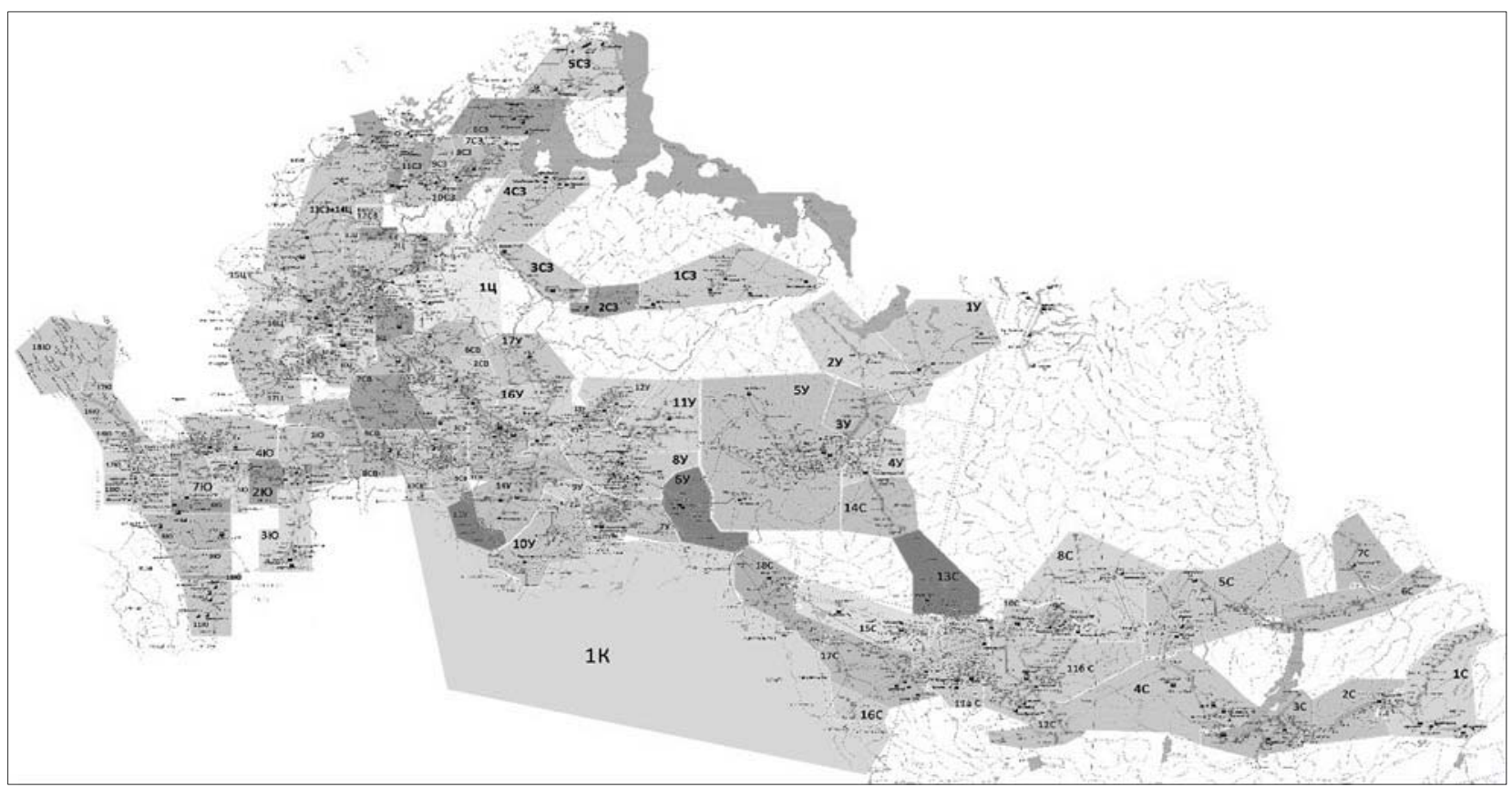

Fig.2. Reliability zones of the UPS of Russia

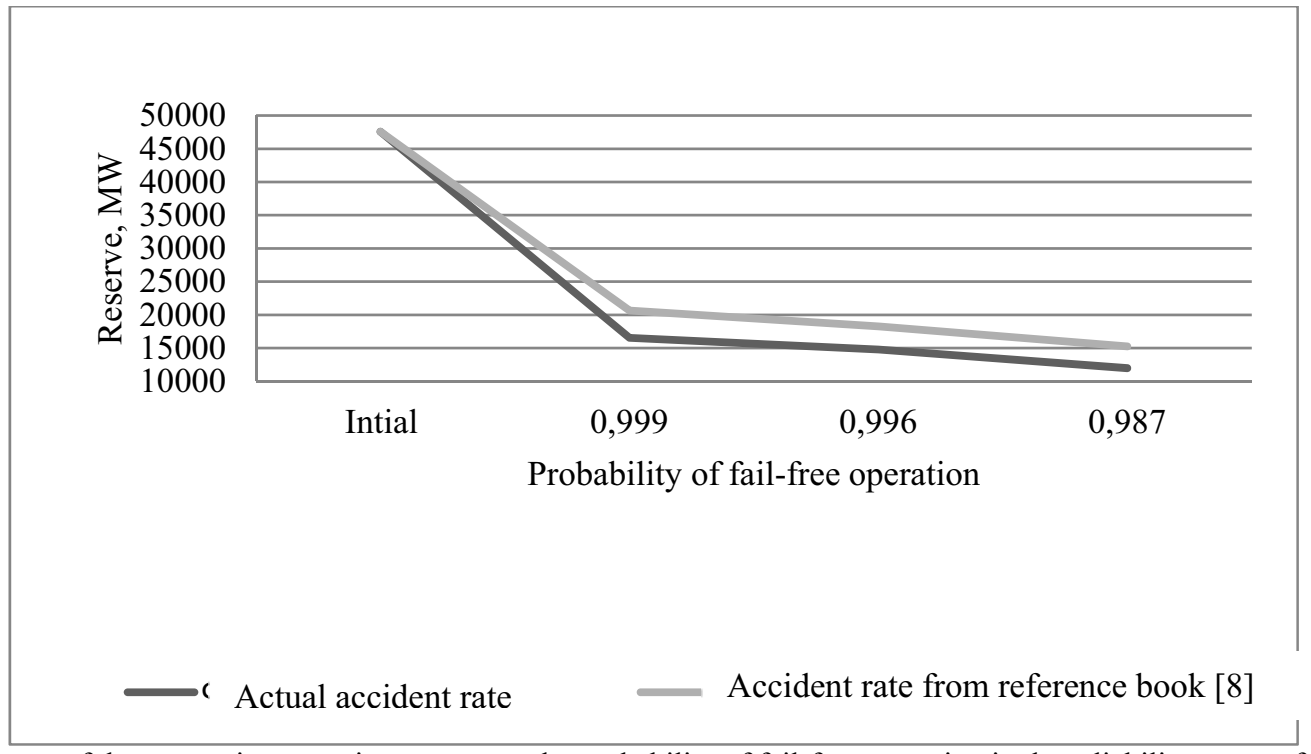

Fig.3. Dependence of the generating capacity reserve on the probability of fail-free operation in the reliability zones of the UPS of Russia. 
Table 3. Capacity balance in the UES of Russia for different standards of the probability of fail-free operation and with different coefficients of accident rates

\begin{tabular}{|l|c|c|c|c|c|c|}
\hline $\begin{array}{l}\text { Standard value of } \\
\text { probability of fail- } \\
\text { free operation }\end{array}$ & \multicolumn{2}{|c|}{0,999} & \multicolumn{2}{c|}{0,996} & \multicolumn{2}{c|}{0,987} \\
\hline & $\begin{array}{c}\text { Actual } \\
\text { accident rate }\end{array}$ & {$[8]$} & $\begin{array}{c}\text { Actual } \\
\text { accident rate }\end{array}$ & {$[8]$} & $\begin{array}{c}\text { Actual } \\
\text { accident rate }\end{array}$ & {$[8]$} \\
\hline $\begin{array}{l}\text { Required available } \\
\text { capacity, MW }\end{array}$ & 175206 & 179328,9 & 173454 & 176946,9 & 170659 & 173927,3 \\
\hline $\begin{array}{l}\text { Over-generation, } \\
\text { MW }\end{array}$ & 31053 & 26930,1 & 32805 & 29312,1 & 35600 & 32331,7 \\
\hline $\begin{array}{l}\text { Coincident demand, } \\
\text { MW }\end{array}$ & 158686 & 158686 & 158686 & 158686 & 158686 & 158686 \\
\hline $\begin{array}{l}\text { Generating reserve, } \\
\text { MW }\end{array}$ & 16520 & 20642,9 & 14768 & 18260,9 & 11973 & 15241,3 \\
\hline $\begin{array}{l}\text { Redundancy factor, } \\
\%\end{array}$ & 10,4 & 13 & 9,3 & 11,5 & 7,5 & 9,6 \\
\hline
\end{tabular}

As you can see from the table 3 the difference in the reserve of capacity for different values of the coefficients of accident rate is about $2 \%$.

\section{Conclusion}

Justification of the rational level of reserving the generating capacity of the UES depends on many factors, among which maximally reliable information about the technical and reliability parameters of the power engineering equipment operated in the EPS. The coefficient of accident rate of the power engineering equipment is an important parameter that most directly affects the indicators of adequacy and the level of reservation of the EPS. The methods for determining the coefficient of accident rate of power equipment are analyzed in the article. Based on their analysis, it was concluded that in modern operating conditions of power equipment, when determining the accident rate for a unit of equipment, it is necessary to take into account the inservice time, the time in reserve, the time in scheduled repairs and the time in emergency downtimes.

When analyzing the accident rate of overhead transmission line of the basic network, operated in the UES of Russia, it was revealed that the accident rate of overhead transmission line is uneven during the year and this condition have to taken into account when assessing of the adequacy. When analyzing the accident rate of the generating aggregates, it was revealed that that for the same type of equipment in different IPS, the accident rate is different and also the coefficient of accident rate for modern operating conditions differs from those values that are presented in the reference books, what determines its constant relevance.

The experimental part of the article is showed the influence of different values of the coefficient of accident rate on the level of operating reserve of generating capacity using the example of the Unified Energy System (UES) of Russia.
The research was carried out with the financial support of the Russian Foundation for Basic Research within the framework of the scientific project No. 20-08-00550 a, as well as with the support of the Russian Academy of Sciences within of the scientific project No. AAAA-A17-117030310450-3).

\section{References}

1. D. Krupenev, A. Nazarychev, Reliability and assessment of the technical condition of equipment for power supply systems: a tutorial. Novosibirsk: Science 224 p. (2020) (In Russia)

2. G. Kovalev, L. Lebedeva, Reliability of Power Systems / Springer Cham; 1st ed., 237 (2019)

3. Billinton R., Li W, Reliability Assessment of Electric Power Systems Using Monte Carlo Methods / Springer; 361p. (1994)

4. D. Krupenev, D. Boyarkin, D. Iakubovskii, Improvement in the computational efficiency of a technique for assessing the reliability of electric power systems based on the Monte Carlo method. Reliability Engineering and System Safety, 204. ID: 107171. (2020)

5. P. Alekseev, Accident rate is an indicator of accidents in the power industry. Calculation method. Presentation of JSC "SO UES" (2017) (In Russia)

6. A. Abdurakhmanov, S. Glushkin, V.Plotnikov, A.Shutov, Once again about the characteristics of the reliability of the elements of electrical networks. On Sat. Methodological issues of research on the reliability of large energy systems: Vol. 69. Reliability of developing energy systems. Book 1. Irkutsk: ISEM SB RAS. 38-48 p. (2018) (In Russia)

7. A. Nepomnyashchy, Power system equipment reliability. M.: Publishing house of the journal "ELECTRIC ENERGY. Transmission and Distribution" 196 p. (2013) (In Russia)

8. V. Ershevich, A. Zeiliger, G. Illarionov, Ed. Rokotyana S.S., Shapiro I.M. M: Energoatomizdat. Handbook for the design of electrical power systems. 352 (1985) (In Russia)

9. Order of the Ministry of Energy of Russia dated February 28, 2018 No. 121 "On approval of the scheme and program for the development of the Unified Energy System of Russia for 2018-2024" (In Russia) 